\title{
A Skewness Based Method for Diagnosis in Quasi-Z T-Type Grid-Connected Converters
}

\author{
Tito G. Amaral $* * *$, Armando Cordeiro $* * * * *$ \\ *ESTSetúbal, Instituto Politécnico de Setúbal, Setúbal, Portugal \\ **Centro de Engenharia para um Desenvolvimento Sustentável (SustainRD-IPS) \\ *** ISEL, Instituto Politécnico de Lisboa, Lisbon, Portugal \\ (tito.amaral@estsetubal.ips.pt, acordeiro@deea.isel.ipl.pt) \\ †ESTSetúbal, Campus do IPS, Estefanilha, Postal address, Tel: +351 2657900 \\ 00, tito.amaral@estsetubal.ips.pt
}

\begin{abstract}
One of the very interesting converters for transformerless grid-connected PV systems is the multilevel quasi-Z T-Type inverter. Besides their multilevel operation, it presents voltage Boost capability and robustness to instantaneous switching between power semiconductors of the same leg and capability to work in fault tolerant condition. However, to ensure this capability, it is essential to ensure a fast and correct diagnosis of the component under fault. Thus, this paper proposes a new method for the detection of an open switch fault. The proposed approach uses the inverter AC line currents that will be analyzed by a Skewness based method. The method has the capability to distinguish the switch under fault. Besides that, it presents robustness to interferences such as noise, as well is insensible to variations of the injected power into the grid. Several simulation and experimental results will be presented in order to verify the capability of the proposed method.
\end{abstract}


Keywords- Quasi-Z inverter (qZSI); T-Type; fault detection and diagnosis; Skewness; grid-connected PV.

\section{Introduction}

In the actual context of a strong development and implementation of renewable energy sources, power electronic converters play a very important role $[1,2]$. In fact, the two most of the important renewable generators, such as, wind and solar photovoltaic, usually requires does converters as an interface between the generators and the grid. In grid-connected renewable sources, many power electronic circuits have been proposed. Among the several proposes, one of the categories that showed to be very attractive were the multilevel inverters [3]. Their interest result of some characteristics that they presents, such as, reduced AC voltage and current total harmonic distortion (THD), reduced blocking voltage requirement of the power semiconductors and higher reliability to faults. Among the several topologies, the three-level T-Type inverter was considered very interesting. Under the point of view of the reliability and application to systems like photovoltaic, quasi-Z source inverters (qZSI) have been considered as a very promising solution [4,5]. Regarding the reliability of the power converter, their power semiconductors are considered as one of the weakest component parts. Thus, in order to implement fault tolerant strategies, it is critical the detection of the power semiconductor under fault [6]. Under this context, this work proposes a new open switch fault diagnosis method for the three-level T-Type qZSI. The proposed method is based on a Skewness algorithm that presents robustness to interferences and insensibility to variations of the injected power into the grid. 


\section{Proposed Open Switch Fault Detection Method}

One of the power converters that have been used for the grid-connected PV systems is the three-phase quasi-Z T-Type inverter (Fig. 1). It presents voltage Boost capability, which is normally required in PV systems. Besides their multilevel operation, their reliability is higher since present robustness to instantaneous switching between power semiconductors of the same leg.

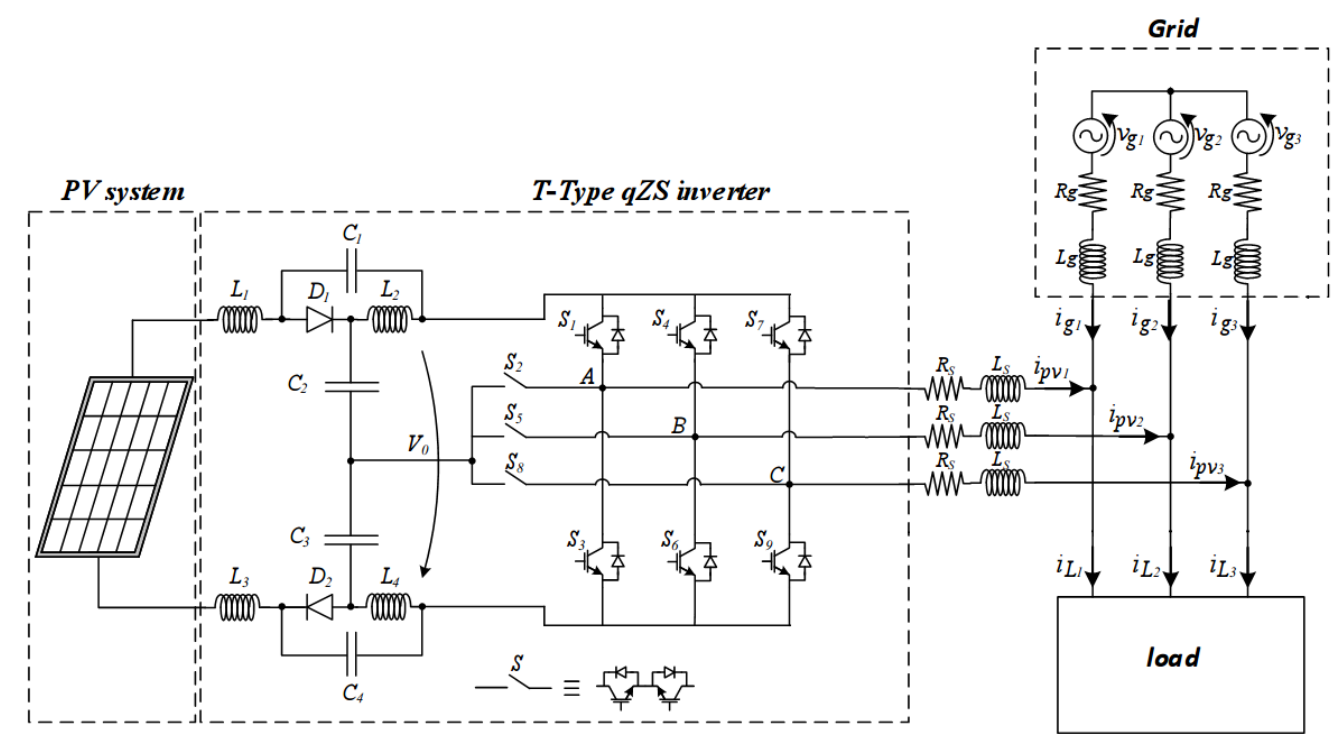

Figure 1. Grid-Connected Three-phase Quasi-Z T-Type inverter

The proposed approach for the diagnosis of an open switch fault of the three-phase T-Type qZSI consists in the following several steps:

- Acquisition of the $\mathrm{AC}$ three-phase currents and perform their normalization;

- Apply the Skewness algorithm for the diagnosis of an open switch fault;

- In case of a fault identify the specific switch under fault.

The skewness is a statistical higher order moment and his value extracted from a signal indicates the complexity of that signal and his distribution. It shows the lack of symmetry of a signal data set and is obtained by the ratio of the third central moment and the third power of the standard deviation in a distribution. The skewness for a 
normal distribution is 0 . Negative skew indicates that the data is skewed left or that the left tail is long relative to the right tail. In the same way, positive skew indicate data that is skewed right or that the right tail is long relative to the left tail (Fig. 2).

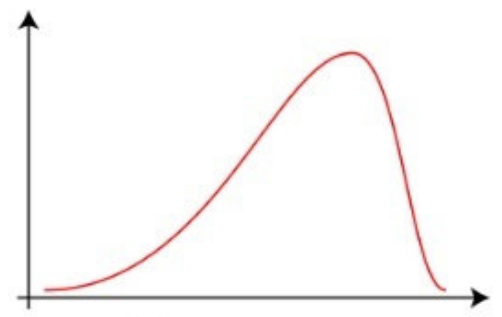

(a) Skewed Left

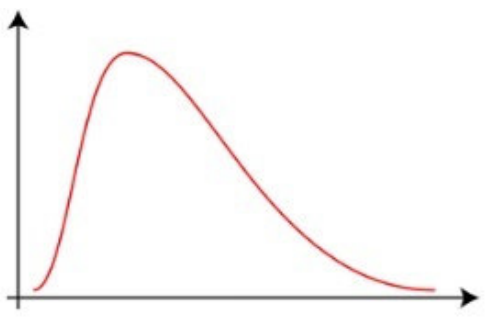

(b) Skewed Right

Figure 2. Examples of histogram distribution.

To detect the type of fault in the three-phase T-Type qZSI it was applied the higher order statistical analysis based on skewness. First, for the moving windows analysis, each of the three-phase currents data set is segmented into an integer number of windows with a percentage of overlap between windows. The signal is segmented into windows of $20 \mathrm{~ms}$ of length and the neighboring windows are overlapped by $0.01 \mathrm{~ms}$, which keep the skewness stable and smooth for a desirable decision. For each segment it is computed the skewness and finally in case of a fault it is identified the specific switch under fault.

\section{Results}

The simulation results of the current for three types of fault are plotted in Fig. 3(a), Fig. 4(a) and Fig. 5(a). In this figures it can be seen the current behavior before the faulty condition. For those faults the skewness was computed for the three currents and are showed in Fig. 3(b), Fig. 4(b) and Fig. 5(b). For the $\mathrm{S}_{21}$ and $\mathrm{S}_{11}$ faults the obtained results of the skewness are symmetric. For a fault in the upper switch of the inverter the skewness is negative and for a fault in the bottom switch the skewness is positive. When 
the fault occurs in the middle switch, the skewness is negative but of a lower absolute value than that obtained by fault in the upper switch.

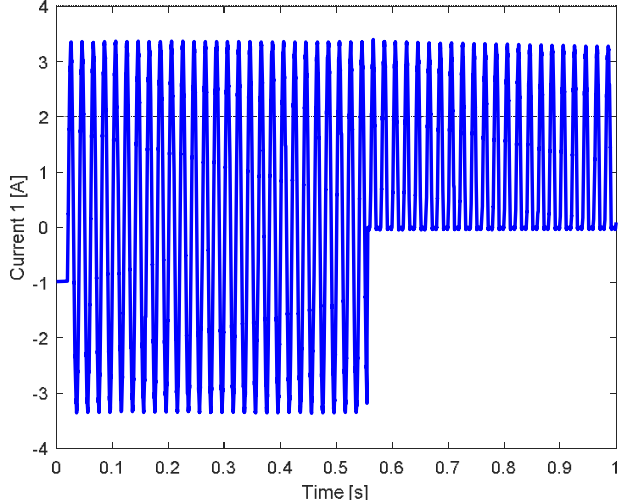

(a)

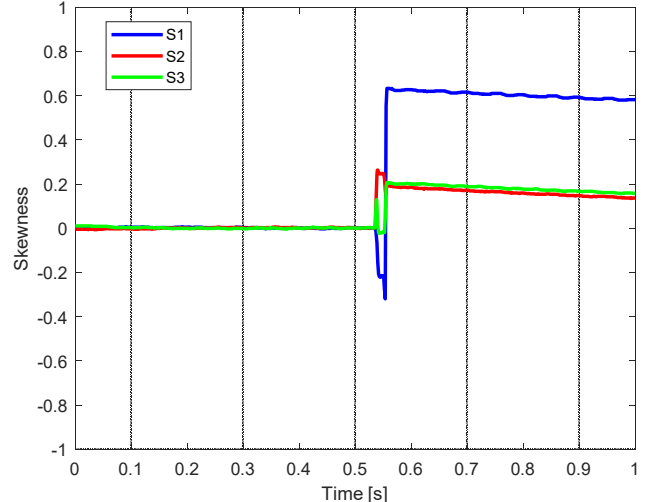

(b)

Figure 3 - Simulation results before and after $\mathrm{S}_{21}$ fault.

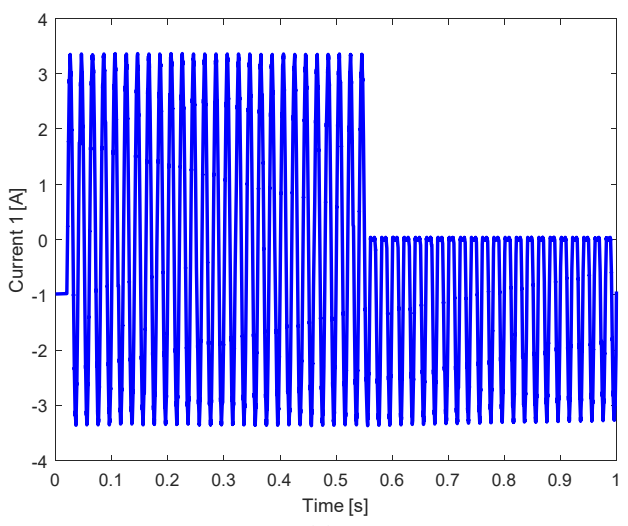

(a)

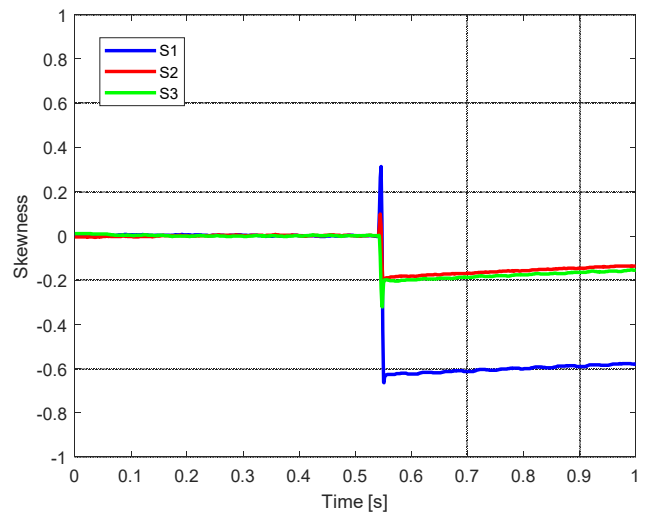

(b)

Figure 4 - Simulation results before and after $\mathrm{S}_{11}$ fault.

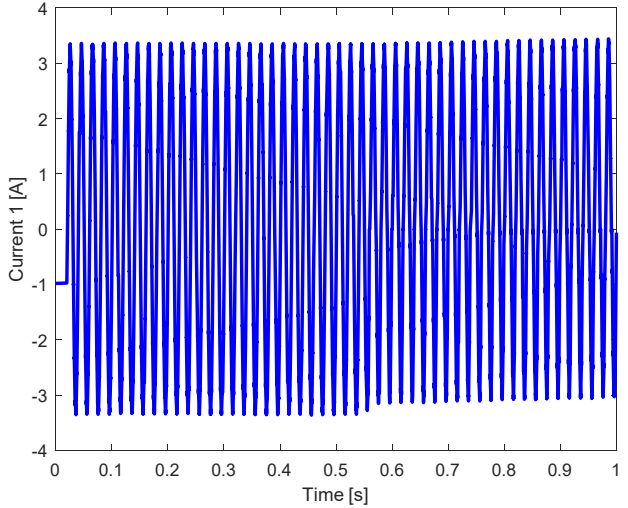

(a)

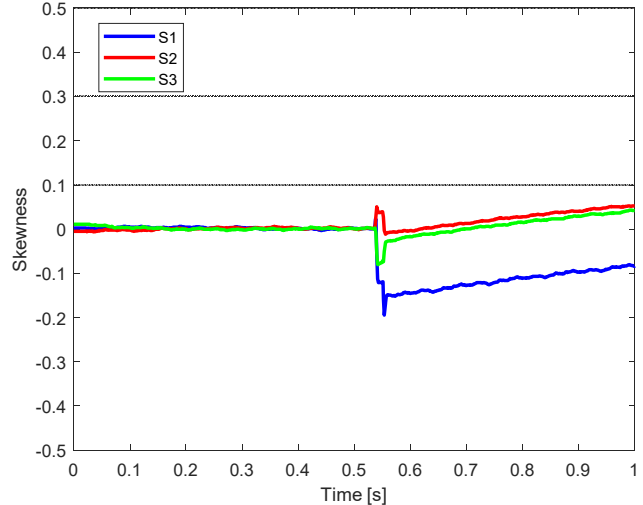

(b)

Figure 5 - Simulation results before and after $\mathrm{S}_{12}$ fault. 


\section{Conclusion}

In this paper was presented a new method for the detection of an open switch fault in a grid-connected quasi-Z T-Type inverter. The proposed method is based on several steps, namely, the acquisition of the AC currents, normalization of those currents, implementation of a Skewness algorithm and definition of the identification indexes. It was shown that the proposed method allows diagnosing the power converter, and in case of an open switch fault identifies the one under that condition. It is also characterized by their non-dependence of the injected power. To confirm the theoretical assumptions it was presented some results. These results allowed confirming the capability to identify the switch under fault in a precise and fast way. It also showed their capability to the noise immunity.

\section{References}

1. O. Ogunrinde, E. Shittu, K. Dhanda, "Investing in Renewable Energy: Reconciling Regional Policy With Renewable Energy Growth”, IEEE Engineering Management Review, Vol. 46, No. 4, pp. 103111, dec. 2018.

2. E. Kabalc1, E. Irmak, I. Çolak, "Design of an AC-DC-AC converter for wind turbines", International Journal of Energy Research, Wiley Interscience, DOI: 10.1002/er.1770, Vol. 36, No. 2, pp. 169-175.

3. S. Kouro, M. Malinowski, K. Gopakumar, J. Pou, L. G. Franquelo, B. Wu, J. Rodriguez, M. A. Pérez, J. I. Leon, "Recent Advances and Industrial Applications of Multilevel Converters", IEEE Transactions on Industrial Electronics, vol. 57, pp. 2553-2580, 2010.

4. Y. Siwakoti, F. Peng, F. Blaabjerg, P. Loh, G. Town, "Impedance-Source Networks for Electric Power Conversion Part I: A Topological Review," IEEE Trans. Power Electron., vol. 30, no. 2, pp. 699-716, Feb 2015.

5. V. Pires, A. Cordeiro, D. Foito, "Quasi-Z-Source Inverter With a T-Type Converter in Normal and Failure Mode", IEEE Transactions on Power Electronics, vol. 31, No. 11, pp. 7462-7470, November 2016.

6. Ui-Min Choi, Kyo-Beum Lee, Frede Blaabjerg, "Diagnosis and Tolerant Strategy of an OpenSwitch Fault for T-Type Three-Level Inverter Systems”, IEEE Trans. On Ind. Appl., vol. 50, № 1, pp. 495-508, Jan./Feb. 2014. 